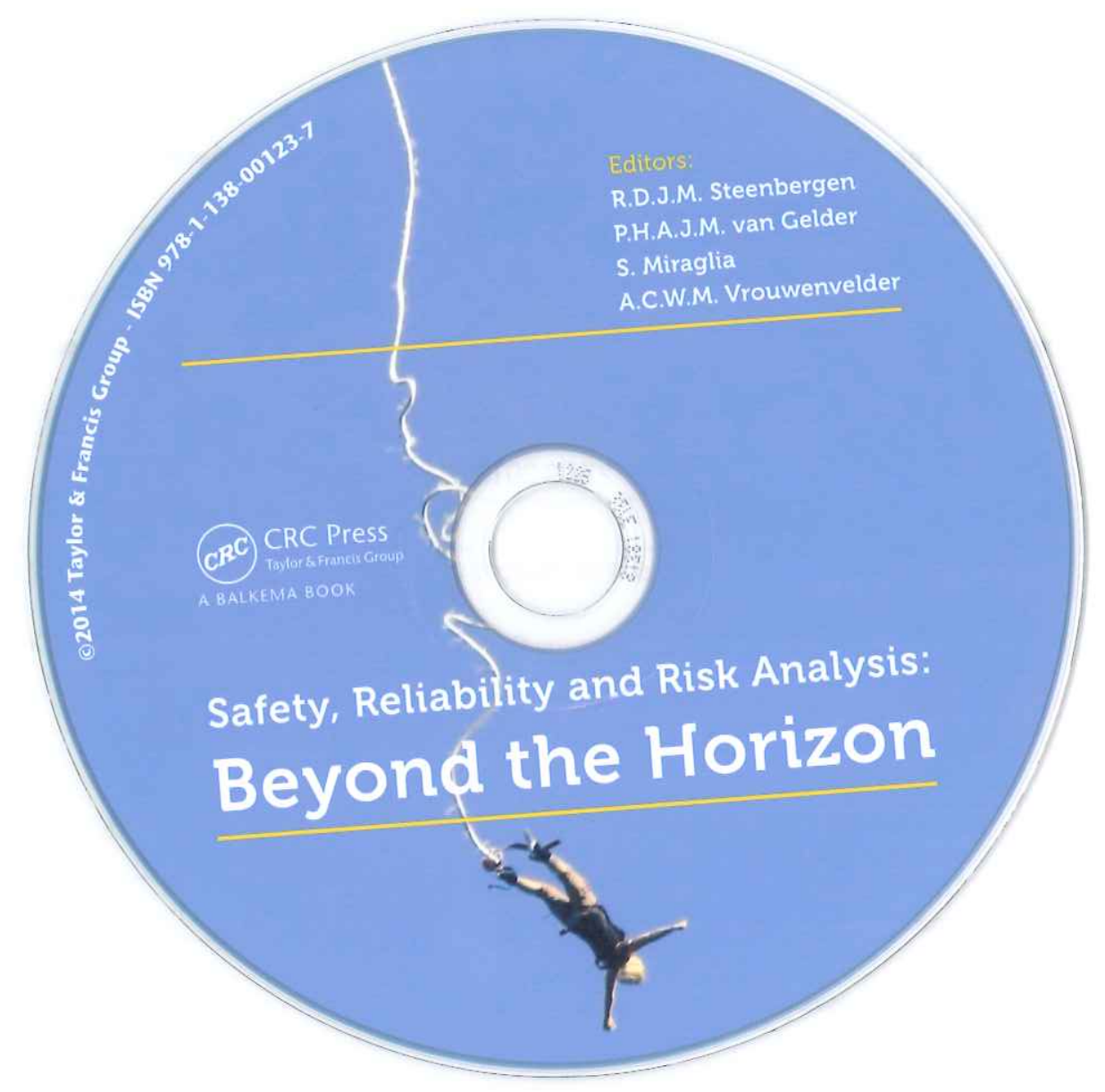




\title{
Development of an instrument to analyze the occupational risk acceptance
}

\author{
M.A. Rodrigues \\ Research Centre on Environment and Health, Allied Health Sciences School, Polytechnic Institute of Porto, Vila \\ Nova de Gaia, Portugal \\ Research Center for Industrial and Technology Management, University of Minho, Guimarães, Portugal
}

P.M. Arezes

Research Center for Industrial and Technology Management, University of Minho, Guimarães, Portugal

C.P. Leão

$R \& D$ Centro Algoritmi, Engineering School, University of Minho, Guimarães, Portugal

\begin{abstract}
An understanding of the factors that can have influence on risk acceptance may provide relevant support to an effective guideline that helps in the acceptance criteria formulation. Therefore, this study aims to develop and to validate a tool to analyze risk acceptance in Portuguese furniture industries. Workers judgments about risk acceptance were analyzed together with five individual variables: trust, risk perception, benefit perception, emotions and, ethic, moral and values. The first part of the tool integrated demographic questions. The second part included items to measure the variables in analysis. The validation was performed first in a pilot test with 29 workers, and the validity and reliability analysis with a sample of 219 workers. Four factors were identified: emotions, benefits perceptions, acceptance/trust and risk. Also the items interrelations with factors were verified. Some differences among companies were confirmed, showing they realize risk acceptance in a different way.
\end{abstract}

\section{INTRODUCTION}

For a successful risk management strategy it is essential to place the risk at an acceptable level. However, in occupational environments, risk decision-making is a challenging issue, since there are several factors that can influence the risk acceptance process. The knowledge of what is the risk level that stakeholders consider to be acceptable, as well as, an understanding of the what factors that can have influence on risk acceptance, may provide relevant insights to helps in the acceptance criteria definition. Furthermore, the knowledge about how people think about risk and how they respond to risk can be useful to anticipate and understand the responses to hazards like safety behaviors, and to improve the design of a strategy to reduce risks and the communication of risk information (Slovic, 1987; Huijts et al., 2012).

Notwithstanding the importance of this issue, researches about risk acceptance relating to occupational risks were not found. It is only possible to find some works focused on risk perception (see e.g., Arezes \& Miguel, 2008), however without considering the risk acceptance and the way that it is related with other variables.

For other side, several studies have been conducted over the years in order to analyze the acceptance and acceptability of an activity or technology within society and the factors that can have influence on it. These studies gave us insights about how people form their opinion towards public risks and the key factors that can have influence on it. These researches show that risk perception, risk benefit and trust, play an important role on risk acceptance (see e.g., Siegrist, 1999; Siegrist, 2000; Siegrist et al., 2000; Siegrist et al., 2005; Bronfman et al. 2008; Bronfman et al., 2009; Ji et al., 2011; Bronfman et al., 2012; Huang et al., 2013). These studies provide strong insights to public risk acceptance and have showed that lack of public support in relation to a technology or activity can reduce its viability and that the risk acceptance is an important predictor of risk behaviors (see e.g., Huijts et al., 2012). However, other factors can also have influence on risk acceptance, as emotions and ethical questions, moral judgments and values (see e.g., Slovic \& Weber, 2002; Roeser, 2006; Huijts et al., 2012). 
In accordance with the above discussion, this study aims to develop and to validate a tool to analyze risk acceptance in Portuguese furniture industries.

\section{METHODOLOGY}

\subsection{Sample}

This study was developed in 6 furniture companies, all located at the north of Portugal. The analyzed companies were considered Small and Medium Sized Enterprises (SMEs). The companies comprised a total of 274 workers, of which 219 participated on the study. Most of participants were males $(85.6 \%)$, and the average age was 39.20 years old $(\mathrm{SD}=10.13$; interval range $19-60$ years old). In general, workers have been with the companies in average for 10.26 years $(\mathrm{SD}=6.66$; interval range $1-30$ years) and exert such activity on average for $17.22(\mathrm{SD}=11.83$; interval range $1-48$ years $)$.

\subsection{Instrument}

Workers judgments about risk acceptance were measured together with five individual variables through a questionnaire: trust, risk perception, benefit perception, emotions, and finally, ethical questions, moral judgments and values.

The questionnaire began with an introductory text, describing the aim of the questionnaire and the problematic of risk acceptance. After that, a group of questions for the respondents' characterizations was included: age, gender, department/sector, professional activity, number of years working at the company, number of years at the mentioned professional activity, and previous involvement in work accidents (for a positive answer, its identification was required). Then followed a set of questions to measure the variables in analysis. The questions included items, which were measured on a 5-point Likert scales, based on previous researches in different areas (Siegrist, 2000; Tharaldsen et al., 2010; Bronfman et al., 2012). The scales utilized are presented in Table 1.

Trust was measure at different levels, i.e., the workers' trust in: management decisions on risk control, the actuation of OHS professionals on risk control, the supervisor actuation to enforcing the rules and safety procedures and, co-workers to compliance with rules and safety procedures.

Respondents were also asked in relation to ethic, moral and values. Considering that ethics is the application of morality and morality refers to the values that are subscribed to and fostered by individuals (Goetsch, 2011), three values were measured in order to analyze these issues, equity, equality and justice. Equity was analyzed by con-
Table 1. Scales used to measure the different factors.

\begin{tabular}{lll}
\hline Variable & Scale endpoints & \\
\hline Acceptability & $1=$ Unacceptable & $5=$ Acceptable \\
Trust & $1=$ No trust at all & $5=$ High trust \\
Risk perception & $1=$ Not risky at all & $5=$ Very risky \\
Benefit & $1=$ Not beneficial & $5=$ Very \\
$\quad$ perception & at all & beneficial \\
Ethical, moral & $1=$ Strongly & $5=$ Strongly \\
$\quad$ and values & disagree & agree \\
Emotions & $1=$ Not worried & $5=$ Very worried \\
& at all & \\
\hline
\end{tabular}

cerns related with need to exist a limit above which no individual be exposed. Equality was related with the need of the same upper risk threshold be applied to all enterprises of the sector. At last, justice considered that is not fair a worker be exposed to a very high risk, regardless of the benefits.

The questions on risk acceptance, risk perceptions and emotions were based on scenarios included on the different items. These scenarios were constructed based on national accident statistics for the year of 2008 for the wood and mattresses manufacturing (CAE 31091) supplied by Portuguese Office of Strategy and Planning (GEP) for this study, and on the companies' safety conditions analysis. The statistics provided by GEP were grouped according to Eurostat (2012) classification, including accident frequencies and number of days lost. Accordingly, the two more frequent mode of injury were "Contact with sharp, pointed, rough, coarse material agent" and "Physical or mental stress". For each of this injury type, the more frequent situation and the worst situation were selected. The scenarios were constructed based on these frequencies and correspondents days lost (considering the upper limit), where this last one was used as a measure of the severity. For the most frequent accidents it was also created a scenario referred to the days lost lower limit provided. In order to facilitate the respondents' judgment, the scenario for each mode of injury was based on the most frequent risk identified in the companies analyzed (cut with a saw and a musculoskeletal disorder). After, new scenarios were created in order to analyze which variable mostly affect risk acceptance, i.e., frequency or severity. For both situations, more frequent and worst, the risk level was determined, considering the days lost upper limit. Then, keeping the same risk level, the values of frequency and severity were reversed to the opposite scenario. Finally, it was created a mid scenario, keeping the frequency but changing gravity to 6 months of absence. It was also created a scenario corresponding to a death in a year. Despite in 2008 no death accident occurred in this 
sub-sector, according GEP data supplied, in 2006 and in 2007 one fatal accident occurred. This scenario was related with a saw projection.

In order to analyze benefits perceptions two questions, each one with three items, were included. The first was referred with benefits for employer and the second to the employees, related with the exposure to the situations presented. The situations were related to risk factor associated with the most frequent risks in the sector: "Operate with saws without protection", "Perform repetitive tasks for long periods" and "Perform tasks of manual handling of loads".

The questionnaire was delivered to five $\mathrm{OSH}$ experts, who were requested to review, examine and test it. Some improvements were suggested and taken into account in the final version. The scales were also tested in a pilot survey, conducted on a sample of 29 workers from one randomly selected company, in order to detect any possible weak points, and to get feedback about the intelligibility and unambiguousness of items. Respondents were encouraged to make any comments about questions and items. Some improvements were carried out on the language of the scenarios.

\subsection{Procedures}

The final version was applied to all workers of the 6 furniture companies in analysis. Researchers distributed personally the questionnaires and encouraged all workers to participate with the help of the top management. Questionnaires were completed during working hours or, in some companies, at the end of the work shift, in the company or at home.

\section{RESULTS AND DISCUSSION}

Studies about risk acceptance or risk acceptability apply different approaches in order to analyze the adequacy of the measure instruments. Some studies only tested and validated the measure instrument base on a reduced sample, before applying to all sample, in order to analyze features related with the language used and unambiguousness (see e.g., Bronfman et al., 2009). Others studies analyzed the reliability of each latent variable (see e.g., Bronfman et al., 2012), and finally, some studies have opted to apply a two-step process, where and before the validity of the model, a Confirmatory Factor Analysis (CFA) of each latent variable was performed (see e.g., Siegrist, 1999). These differences on the approaches were also found in studies on other areas (see e.g., Lee et al., 2009; Hassan \& Abdel-Aty, 2011; Hallak et al., 2012).

Face to this, in this study three-step approach was applied to evaluate the questionnaire validity, reliability and feasibility. First, a pre-study was performed to a group of 29 effective workers. Some improvements were performed, and the instrument applied to all sample. After that, an Exploratory Factor Analysis (EFA) was done to determine the construct validity of the questionnaire (Pestana \& Gageiro, 2008). Finally, a reliability analysis of the instrument was performed, was well as, an analysis of the differences among companies.

\subsection{Outliers and missing analysis}

All cases with missing values were analyzed. It was verified a low number of missing values, being decided to replace the missing values with the mean, in order to perform the analyses using a sample without any estimation of missing values. This is in accordance with Acuna \& Rodriguez (2004), where the author concluded that in datasets with a small number of missing values there is not much difference between case deletion and the use of imputation methods, as replace with mean.

After the missing values analysis, the outliers were identified by the standardized residuals analysis. All outliers' cases were removed from the sample. Ten cases were removed from the sample. The magnitude of the final sample was 209 subjects.

\subsection{Exploratory factor analysis}

With the assumption of all items were uncorrelated with each other, an exploratory factor using Varimax rotation was done to analyze the interrelationships among the items and to identify groups or clusters of variables (factors).

In a first analysis eleven factors were identified based on the eigenvalues values (Kaiser' criterions: eigenvalues greater than 1), accounting for $77.8 \%$ of the cumulative variability explained by each factor solution. However, and based on our theoretical presuppositions and experience, six factors could be defined, i.e., acceptance, risk perception, benefit perception, trust, emotions and ethical factors.

Forcing six factors, the communalities values for all ethical items and one trust item (trust in co-workers to compliance with rules and safety procedures) were very low $(<0.35)$. This indicates that these items present a low relation with other factors, being removed from the analysis. Accordingly, a new EFA was performed for five factors. However, the analysis of the loadings suggests that trust and acceptance are related, so they can be considered as one factor. Faced to this scenario the final exploratory factor analysis was performed with four factors, with $55.95 \%$ of explained variability (Table 2).

KMO statistics was used to measure the sampling adequacy. Results showed a KMO statistics 
Table 2. Component matrix after Varimax rotation and $\%$ of variance.

\begin{tabular}{|c|c|c|c|c|}
\hline \multirow[b]{2}{*}{ Items } & \multicolumn{4}{|c|}{ Component } \\
\hline & 1 & 2 & 3 & 4 \\
\hline $\mathrm{T} 1$ & & -0.456 & 0.472 & \\
\hline $\mathrm{T} 2$ & & -0.340 & 0.482 & \\
\hline T3 & & & 0.548 & \\
\hline A1 & & -0.663 & & \\
\hline $\mathrm{A} 2$ & & -0.582 & 0.386 & \\
\hline A 3 & & -0.502 & 0.661 & \\
\hline A4 & & -0.313 & 0.664 & \\
\hline A5 & & & 0.755 & \\
\hline A6 & & & 0.733 & \\
\hline A7 & & & & \\
\hline A 8 & & -0.410 & & -0.516 \\
\hline A9 & & & 0.548 & \\
\hline A10 & & & 0.654 & -0.319 \\
\hline A11 & & 0.306 & 0.604 & \\
\hline A12 & & & 0.644 & \\
\hline A13 & & & & -0.427 \\
\hline BE1 & & 0.526 & & \\
\hline BE2 & & 0.700 & & \\
\hline BE3 & & 0.779 & & \\
\hline BO1 & & 0.547 & & \\
\hline $\mathrm{BO} 2$ & & 0.691 & -0.301 & \\
\hline BO3 & & 0.761 & & \\
\hline $\mathrm{R} 1$ & & 0.690 & & 0.391 \\
\hline $\mathrm{R} 2$ & & 0.552 & & 0.561 \\
\hline R3 & & 0.310 & & 0.686 \\
\hline $\mathrm{R} 4$ & & & & 0.728 \\
\hline R5 & & -0.315 & -0.365 & 0.634 \\
\hline R6 & & & -0.393 & 0.479 \\
\hline R7 & & & 0.312 & 0.505 \\
\hline $\mathrm{R} 8$ & & 0.389 & & 0.678 \\
\hline R9 & & & & 0.742 \\
\hline $\mathrm{R} 10$ & & & -0.409 & 0.680 \\
\hline R11 & & -0.495 & -0.427 & 0.510 \\
\hline $\mathrm{R} 12$ & & 0.344 & -0.301 & 0.330 \\
\hline $\mathrm{R} 13$ & & & & 0.605 \\
\hline $\mathrm{E} 1$ & 0.672 & 0.481 & & \\
\hline E2 & 0.719 & 0.488 & & \\
\hline E3 & 0.839 & & & \\
\hline $\mathrm{E} 4$ & 0.828 & & -0.348 & \\
\hline E5 & 0.773 & & -0.384 & \\
\hline E6 & 0.632 & & -0.418 & \\
\hline E7 & 0.668 & & & \\
\hline E8 & 0.724 & & & \\
\hline E9 & 0.888 & & & \\
\hline E10 & 0.852 & & & \\
\hline E11 & 0.755 & & -0.304 & \\
\hline E12 & 0.348 & 0.485 & & \\
\hline E13 & 0.480 & & & 0.398 \\
\hline$\%$ of Variance & 25.93 & 11.81 & 9.49 & 8.62 \\
\hline
\end{tabular}

equal to 0.81 . According to Field (2009), this value is "great". Therefore, the analysis is executable. Bartlett's test of sphericity was used to access the variables correlation. According to the Bartlett's test results the correlations between items were sufficiently large for the principal component analysis $\left[X^{2}(1128)=10451.113, p<0.001\right]$. So, the variables are significantly correlated and consequently factorial analyst is adequately (Field, 2009).

The Table 2 presents the factors loadings after Varimax rotation and the $\%$ of the total variance explained by each factor. The relationship of each item to the underlying factor is expressed by the factor loading. Therefore, to identify the validity of the construct all loading values were analyzed. According Hair et al., (1998) recommendations, a factor loading of \pm 0.3 means the item is of minimal significance, \pm 0.4 indicates it is more important, and \pm 0.5 indicates the factor is significant. However, the Steven's Guideline is one of the more frequent orientations to the factor loadings analysis. According the author, the significance of the factor loading will depend on the sample size, so, for a sample of 200 it should be greater than 0.364 (Field, 2009). However, according Field (2009) it is common the researchers to consider loadings above 0.3 as important.

According Table 2, the factorial analysis grouped the factors in an expected way: Factor 1 is related to emotions and explained $25.93 \%$ of the total variance; Factor 2 associated with benefits perceptions and explained $11.81 \%$ of the total variance; Factor 3 with acceptance/trust explained $9.49 \%$ of the total variance and, finally, Factor 4 related to risk perception and explained $8.62 \%$ of the total variance (the items included in each factor are identified as bold). It is highlighted that some items indicating a contribution to more than one factor. Some of then presents higher loadings value in other factor than the expected: E12, A2 and R1. In these cases was decided to force these items belong to the expected factor (e.g., E12 belong to the factor emotions and not benefit perception). Other items, as A1, A 8 and A13 that was expected belong to Factor 3 are dived in Factor 2 and 4, that is, these items are largely explained by benefit perception and risk perception. This can be related with type of risk acceptance scenarios created, where the scenarios with low risk are more explained by benefits perceived and the higher risk scenario, related with dead (A13), more explained by the risk perceived. Finally, the item A7 is not related to any of the considered factor, being excluded from the analysis.

\subsection{Reliability analysis}

A questionnaire must be not only valid, but also reliable. The reliability refers to the ability of a 
Table 3. Reliability analysis.

\begin{tabular}{ll}
\hline Factor & Alpha of Cronbach \\
\hline Emotions & 0.93 \\
Benefit Perception & 0.78 \\
Acceptability/Trust & 0.90 \\
Risk Perception & 0.79 \\
\hline
\end{tabular}

measure to be consistent, i.e., to be considered reliable (Marroco \& Garcia-Marques, 2006). The Cronbach's alpha is the most common measure of scale reliability (Field, 2009). Therefore, it was applied to evaluate the internal consistency of the latent factors. In general, values of 0.70 are recommended as the minimum level of Cronbach's alpha (Kline, 1993).

Accordingly the results presented on Table 3, the reliability of the factors emotions and acceptance/trust is very good $(\alpha \geq 0.90)$ and the benefit perception and risk perception reliability is considered sufficient $(\leq 0.70 \alpha<0.80)$.

\subsection{Differences among companies}

The design of the questionnaire was also constructed in order to allow the identification of possible differences between companies, since it was supposed that risk acceptance varies in accordance to companies' safety climate.

Differences between the companies were observed as expected of all items included in the four factors analyzed $(\mathrm{K}(5)>10, p<0.05$ for all items), excepted for the items A12, R9, E6, E7 and $\mathrm{E} 8(\mathrm{~K}(5)<10, p>0.05$ for all items). These results are important for future analysis, where the safety climate of the companies in a higher sample and the risk acceptance levels will be analyzed (this analysis is not the scope of this study).

\section{CONCLUSIONS}

This work presents the development of a tool to analyze risk acceptance in Portuguese furniture industries and its validation.

The Exploratory Factor Analysis divided the considered 47 items in four factors: emotions, benefits perceptions, acceptance/trust and risk. These factors are in accordance with the theoretical presuppositions and experience. The values of the Cronbach' alpha show that the reliability of the variables was good. The validity and reliability of the instrument it was confirmed, after the removal of some items that not demonstrated relation with the factors.

However, some of the items were included in factors different from the expected. However, due to its high factor loading they were not eliminated. For example, EFA associates the item A13 to the risk perception factor and not to the risk acceptance. This situation can be related to the higher risk level scenario created that was related with dead. So, for a dead scenario, workers fail to distinguish these two concepts. One item, A7, not related to any of the considered factor, was dropped from the analysis.

The analysis of the questionnaire results shows that exist significant differences among companies in relation to the most of the items, which will be important in a future analysis of the influence of companies' safety climate into risk acceptance. This indicates that the companies see the risk acceptance in a different way, situation that can have influence in safety performance and risk decisions.

\section{ACKNOWLEDGEMENTS}

The authors are grateful to the Portuguese Office of Strategy and Planning (GEP), of the ministry of labor and social solidarity, for supplying the national accident data pertinent to the sector analyzed, and to all companies, particularly to the workers, for their voluntary and cooperation on the study. The author M.A. Rodrigues is grateful for the financial support given by University of Minho.

\section{REFERENCES}

Acuna, E., Rodriguez, C. 2004. The treatment of missing values and its effect in the classifier accuracy. Classification, Clustering and Data Mining Applications, 639-648.

Arezes, P.M., Miguel, A.S. 2008. Risk perception and safety behavior: A study in an occupational environment. Safety Science 46: 900-907.

Bronfman, N.C., Vázquez, E.L., Gutiérrez, V.V., Cifuentes, L.A. 2008. Trust, acceptance and knowledge of technological and environmental hazards in Chile. Journal of Risk Research 11(6): 755-773.

Bronfman, N.C., Vázquez, E.L., Dorantes, G. 2009. An empirical study for the direct and indirect links between trust in regulatory institutions and acceptability of hazards. Safety Science 47: 686-692.

Bronfman N.C., Jiménez, R.B., Arévalo P.C., Cifuentes, L.A. 2012. Understanding social acceptance of electricity generation sources. Energy Policy 46: 246-252.

Eurostat. 2012. European Statistics on Accidents at Work (ESAW) Summary methodology. 2012 ed. Luxemburg, Publications Office of the European Union.

Field, A. 2009. Discovering statistics using SPSS. 3rd Ed. Lon-don: SAGE Publications, Ltd.

Hair, J.F., Anderson, R.E., Tatham, R.L., Black, W.C. 1998. Multivariate Data Analysis, Fifth Edition, New Jersey: Prentice-Hall. 
Hallak, R., Brown, G., Lindsay, N.J. 2012. The Place Identity e Performance relationship among tourism entrepreneurs: A structural equation modelling analysis. Tourism Management 33: 143-154.

Hassan, H.M., Abdel-Aty, M.A. 2011. Analysis of drivers' behavior under reduced visibility conditions using a Structural Equation Modeling approach. Transportation Research Part F 14: 614-625.

Huang, L., Ban, J., Sun, K., Han, Y., Yuan, Z., Bi, J. 2013. The influence of public perception on risk acceptance of the chemical industry and the assistance for risk communication. Safety Science 51: 232-240.

Huijts, N.M.A., Molina, E.J.E., Steg, L. 2012. Psychological factors influencing sustainable energy technology acceptance: A review-based comprehensive framework. Renewable and Sustainable Energy Reviews 16: 525-531.

Ji, M., You, X., Lan, J., Yang, S. 2011. The impact of risk tolerance, risk perception and hazardous attitude on safety operation among airline pilots in China. Safety Science 49: 1412-140. Kline, P. 1993. The handbook of psychological testing. 2nd Ed. London: Taylor \& Francis Group.

Lee, J.H., Jin, B.S., Ji, Y. (2009). Development of a Structural Equation Model for ride comfort of the Korean high-speed railway. International Journal of Industrial Ergonomics 39: 7-14.

Marroco, J., Garcia-Marques, T. 2006. Qual a fiabilidade do alfa de Cronbach? Questões antigas e soluções modernas?
Laboratório de Psicologia 4(1): 65-90.

Pestana, M.H., Gageiro, J.N. 2008. Análise de dados para ciên-cias sociais: A complementaridade do SPSS. 5th ed. Lisboa: Edições Sílabo.

Roeser, S., 2006. The role of emotions in judging the moral acceptability of risks. Safety Science 44: 689-700.

Siegrist, M. 1999. A causal model explaining the perception and acceptance of gene technology. Journal of Applied Social Psychology 29: 2093-2106.

Siegrist, M. 2000. The influence of trust and perceptions of risks and benefits on the acceptance of gene technology. Risk Analysis 20(2): 195-203.

Siegrist, M., Cvetkovich, G., Roth, C. 2000. Salient value similarity, social trust, and risk/benefit perception. Risk Analysis 20(3): 353-362.

Siegrist, M., Gutscher, H., Earle, T.C. 2005. Perception of risk: the influence of general trust, and general confidence. Journal of Risk Research 8(2): 145-156.

Slovic, P. 1987. Perception of risk. Science 236: 280-285.

Slovic, P., Weber, E.U., 2002. Perception of risk posed by extreme events. Risk Management strategies in an Uncertain World. New York: Palisades.

Tharaldsen, J.E., Olsen, E., Rundmo, T. 2008. A longitudinal study of safety climate on the Norwegian continental shelf. Safety Science 46: 427-439. 